\title{
9-Cis retinoic acid signaling: changing partners causes some excitement
}

\author{
Benoît P. Leblanc and Hendrik G. Stunnenberg ${ }^{1}$ \\ European Molecular Biology Laboratory (EMBL), Gene Expression Program, 69117 Heidelberg, Germany
}

\begin{abstract}
Reports on the role of retinoids in cell metabolism can be traced back almost a century, when the then-unknown vitamin A present in dietary lipids was found to be essential for normal growth (McCollum and Davis 1913; Osborne and Mendel 1913). Since then, the profound effect of retinoic acid (RA), a derivative of vitamin A, on development and differentiation has been documented in numerous publications. The effect of retinoids is mediated by nuclear receptors acting as ligand-controlled transcription factors. Although the mechanisms of retinoid-induced trans-activation are many-tiered and might have seemed at times hopelessly complex, recent results have brought some order to a confusing picture.
\end{abstract}

\section{Unfolding complexity}

The cloning of the glucocorticoid receptor (GR) (Miesfeld et al. 1984; Hollenberg et al. 1985) and estrogen receptor (ER) (Green et al. 1986), and the realization that the cellular form of the viral oncogene v-erbA was the nuclear thyroid hormone receptor (T3R) (Sap et al. 1986; Weinberger et al. 1986) laid down the groundstone for a very large building now housing $>50$ distinct members of the nuclear receptor superfamily. The high degree of amino acid sequence similarity in what is the hallmark of this family, the DNA-binding domain, implied that these distinct receptors bind to cis-acting elements that are closely related or even identical in nucleotide sequence composition. This relatedness posed a problem. The finding that steroid receptors (type I) bind as homodimers to the half-sites, -AGAACA- for GR and -AGGTCA- for ER, arranged as palindromes invariably spaced by 3 nucleotides (Beato 1989) was initially extrapolated to apply also to other non-steroid receptors. Hence, the identification and characterization of a thyroid hormone receptor response element (T3RE) (Brent et al. 1989) and a retinoic acid response element (RARE) as being a direct repeat of two half-sites $-{ }^{\mathrm{A}} / \mathrm{G}$ GTTCA /de Thé et al. 1990) came as a surprise. However, it soon emerged that neither the direct repeat configuration nor the half-site sequence (consensus $\mathrm{A} / \mathrm{G}^{\mathrm{T}} / \mathrm{G}$ TCA) were specific for these receptors but rather a feature of a receptor subfamily, called type II (Stunnenberg 1993).

\footnotetext{
${ }^{1}$ Corresponding author.
}

Apart from the RARs (Giguére et al. 1987; Petkovich et al. 1987|, which bind and respond to retinoic acid in its all-trans (atRA) as well as 9-cis (9cRA) configurations, the type II subfamily also includes the retinoid $\mathrm{X}$ receptors (RXRs) (Mangelsdorf et al. 1990), which bind to 9cRA but not atRA (Heyman et al. 1992; Levin et al. 1992). Other type II receptors include T3Rs, the vitamin D3 receptor (VD3R) (McDonnell et al. 1987), and the peroxisome proliferator-activated receptors (PPAR) (Issemann and Green 1990). An important, but not overriding, principle underlying binding site selectivity appears to be the length of the intervening sequence separating the half-sites (Näär et al. 1991; Umesono et al. 1991; Vivanco Ruiz et al. 1991). The T3RE and VD3RE consist of half-sites arranged as direct repeats spaced by 4 and 3 nucleotides (referred to as DR4 and DR3, respectively), whereas the PPARE is a DR1 (Tugwood et al. 1992). Natural RAREs appear more flexible and can be of the DR5, DR2, or DR1 type. Further insight came with the findings that type II receptors bind with high affinity to their cognate response elements not as homodimers but as heterodimers with the 9cRA receptor RXR as the common and promiscuous partner (Yu et al. 1991; Bugge et al. 1992; Kliewer et al. 1992a; Leid et al. 1992; Marks et al. 1992; Zhang et al. 1992a).

The configuration of the type II-binding site, a direct repeat, and the heterodimeric nature of type II receptors necessitate a polarity in the binding of a given heterodimer complex. In vitro binding studies using RXR, RAR, and T3R demonstrated selectivity as well as cooperativity in binding, which could be assigned to distinct subregions in the DNA-binding domains (DBDs) (Kurokawa et al. 1993; Perlmann et al. 1993; Predki et al. 1994; Zechel et al. 1994a,b). These findings implied that specific dimerization interfaces are operational only when the DBDs are placed in proper register to one another on a direct repeat with the appropriate half-site spacing. In this respect, it is interesting that a RAR/RXR heterodimer is positioned in a reverse orientation on a DR1 as compared with that on a DR5. On a DR5, RXR is in the $5^{\prime}$ position; on a DRl, RAR sits in the $5^{\prime}$ and RXR in the $3^{\prime}$ positions. Furthermore, this RAR/RXR-DRl configuration has been reported to be inactive (Kurokawa et al. 1994).

Very recently, Sigler and collaborators solved the 
structure of the RXR-DBD and T3R-DBD bound to a DR4 element and provided firm evidence that a DNAsupported asymmetric dimerization interface is present within the DBDs of RXR and T3R (Rastinejad et al. 1995). This structural study reveals how comparatively few amino acid substitutions in the otherwise highly conserved DBD of type II receptors can generate a large repertoire of distinct binding surfaces.

\section{The dilemma of RXR promiscuity and pleiotropic 9cRA signaling}

Because RXR is present in all of the type II receptor heterodimers, its ligand, 9cRA, potentially could activate all of these diverse signaling pathways. Thus, the specificity of these alternate signaling pathways could be obliterated by persistent 9cRA activation. This implies an additional level of regulation directed at limiting the ability of 9cRA to persistently activate all of the RXR heterodimer signaling pathways.

Significant insight into this quandary comes from the observation that in a RXR-RAR heterodimer bound to a DR5 or DRI element, only RAR can bind ligand (Kurokawa et al. 1994); the RXR partner is unable to do so. This implies that RXR functions in this circumstance as an auxiliary factor (Kurokawa et al. 1994). In line with these findings are the observations that ligand activation of RXR does not contribute measurably to the level of transcription from the RA-inducible RAR $\beta 2$ promoter in vivo in embryonic carcinoma (EC) cells (Davis et al. 1994) or in vitro (Valcárcel et al. 1994). Because monomeric RXR in solution readily binds 9-cis RA, its ability to bind ligand in a complex with RAR is apparently abolished because of protein interactions with RAR. Considering that 9cRA does not seem to augment expression of genes that are under the control of T3, one can assume that this scenario may also be extended to the RXR/T3R heterodimers. Unliganded T3R quenches the ligand activation of Gal-RXR fusion proteins (Forman et al. 1995a; Qi et al. 1995). Thus, it appears that heterodimerization of the ligand-binding domain (LBD) induces an allosteric change that alters the ligand-binding pocket of RXR. This implies a new principle in the specificity of ligand binding by nuclear receptors. Namely, the ligand binding specificity is dictated by the heterodimer and not simply by the LBDs of the participating receptors. Earlier work on the Drosophila ecdysone receptor (EcR) also revealed a role for the heterodimer in ligand binding. The Hogness laboratory showed that EcR needs to bind its partner, Ultraspiracle (USP), the Drosophila homolog of RXR (Oro et al. 1990; Shea et al. 1990) in order to bind ecdysone. EcR alone shows no detectable binding of ecdysone (Koelle 1992). In this case, USP or RXR also facilitates DNA binding of EcR (Thomas et al. 1993; Yao et al. 1992), and both ecdysone and 9cRA enhance the binding of the EcR/RXR heterodimer to an EcRE (Thomas et al. 1993; Yao et al. 1993).

Although the recognition of the 9cRA-insensitive role of RXR as an auxiliary DNA-binding factor in RAR, T3R, and VD3R heterodimers resolves the dilemma of pleio- tropic 9cRA activation of these heterodimers, it opens a different question. Namely, what role does 9cRA play in RXR action? A few observations on this issue have been made. The RXR/PPAR heterodimer has been shown to mediate a synergistic response to 9-cis RA and to clofibric acid (Kliewer et al. 1992b; Keller et al. 1993). Furthermore, RAR and RXR can act additively through a DR2 element as demonstrated for the cellular retinoic acid-binding protein II (CRABPII) promoter (Durand et al. 1992). More definitive proof of a ligand-dependent role of RXR in transcription was obtained with retinoids that are selective for RXR receptor (Lehmann et al. 1992). It has also been postulated that 9cRA plays a role in the activation mediated by a RXR homodimer, the formation of which is also ligand-dependent on a DRl element (Zhang et al. 1992b). The enhancement of RXR homodimer binding to a DRl can, however, only be observed with RXR produced in reticulocyte lysates but not when using other eukaryotic or prokaryotic expression systems (Chen et al. 1994). A further potential problem with RXR homodimer action is that thus far, the favored formation of RAR/RXR heterodimers on DR1 elements has precluded the observation of RXR homodimer-mediated activation when RXR is not artificially overexpressed (Kurokawa et al. 1994). Finally, a 9cRA response has been reported in pituitary cells without overexpression (Davis et al. 1994). Taken together, these observations show that RXR can act as an inducible transcription factor in certain circumstances. Whether it did so as a homodimer or heterodimer with an as yet unidentified partner remains unresolved.

An important piece of this complex puzzle has been uncovered recently by the discovery of 9cRA-specific signaling pathways. Several laboratories now demonstrate that 9cRA signals through RXR when it is heterodimerized with orphan members of the nuclear receptor family (Forman et al. 1995a; Perlmann and Jansson 1995; Willy et al. 1995).

\section{Orphans receptors mediate RXR-dependent, 9-cis RA-dependent activation of transcription}

Perlmann and Jansson (1995) have demonstrated that ligand signaling can occur through RXR when it is in a heterodimer complex with the orphan receptors NGFI$\mathrm{B} /$ Nur 77 or the closely related NURR 1 . In this study, the investigators employ the two-hybrid approach in mammalian cells to investigate protein-protein interactions between RXR and other nuclear receptors. Their experiments reveal three novel and unexpected findings. First, NGFI-B and NURR1 effectively heterodimerize with RXR. This is surprising, as NGFI-B is the paradigm member of a receptor subgroup that appears to bind as monomers to a single, extended half-site AAAGGTCA /Wilson et al. 1992). The specificity of monomer binding appears to rely on bases immediately $5^{\prime}$ of the consensus half-site. Second, the ability of Gal-NGFI-B and GalNURR 1 to drive transcription is boosted dramatically by an RXR-selective ligand when RXR is present. Third, RXR/NGFI-B and RXR/NURR1 heterodimers bind and 
trans-activate through a subset of DR5 elements that contain the optimized binding site for NGFI-B or NURRl monomer binding in the spacer sequence between the direct repeats. Intriguingly, the paradigm RARE located in the RAR $\beta 2$ gene promoter meets this requirement and mediates induction by a RXR-selective ligand through a RXR/NGFI-B complex. In contrast, RXR-specific ligands do not augment RXR/RAR-dependent transcription through this element, in full agreement with other reports (Davis et al. 1994; Kurokawa et al. 1994; Valcárcel et al. 1994). In their recent study, Forman et al. (1995a) also observe that NGFI-B heterodimerizes with RXR and that the transcriptional activity of a Gal-NGFI-B/RXR heterodimer can by boosted by RXR-restricted ligands.

Further impetus to this novel concept is added by the description of similar findings by Willy and collaborators (1995). They reveal that yet another orphan receptor, hLXRa, can heterodimerize with RXR and mediate induction elicited by RXR-selective ligands, this time through a particular DR4-type element, an artificial element termed LXRE (GGTTTAaataAGTTCA). This particular LXRE conforms to a DR4T element [where the half-site motif has a $T$ rather than a $G$ in the third position (Mader et al. 1993)]. The investigators show that RXR/LXR does not activate through a DR4G element. The lack of ligand induction through a DR4G element may arguably be attributed to competition by RXR/TR heterodimer that preferentially recognizes the DR4G over the DR4T element (Vivanco Ruiz et al. 1991; Mader et al. 1993). LXR $\alpha$ described in this study is most likely the human homolog of the previously cloned rat receptor, termed RLD-1. When combined with RXR, RLD-1 binds and trans-activates in a ligand-independent manner through a DR4 element. The effect of RXR-selective ligands was, however, not assessed in this study (Apfel et al. 1994). Yet another orphan receptor, referred to as ubiquitous receptor (UR) (Song et al. 1994) or orphan receptor-1 (OR-1) (Teboul et al. 1995), which is closely related but probably distinct from LXR/RLD-1, heterodimerizes with RXR, and its trans-activation can be boosted by retinoids. Finally, Forman and collaborators (1995b) recently identified a novel nuclear receptor, named farnesoid X-activated receptor (FXR), that heterodimerizes with RXR and can be activated by farnesol metabolites. Strong transcriptional synergy is observed upon addition of juvenile hormone III and a RXR-restricted ligand.

\section{Implications and prospects}

This review focuses on the paradox of 9cRA signaling and the possibility that insight is at hand. The studies of Perlmann and Jansson (1995), and Willy et al. (1995) define a novel pathway of 9cRA signaling that involves an orphan receptor and the promiscuous receptor RXR. Taken together with previous work, they reveal that the ligand inducibility of RXR can be switched on or off depending on its partner (see Fig. 1). This molecular switch is one solution that reconciles the paradox of the promiscuity of RXR heterodimerization with the specificity of 9cRA activation. Given the rather ubiquitous expression of some RAR and T3R subtypes and the overlapping binding site repertoires, it seems likely that cross-regulation occurs between RXR/NGFI-B(NURR1) and RXR/ RAR or RXR/LXR/RLD-1) and RXR/T3R by, for example, sequestration of RXR or binding site occlusion. Whether this concept applies to other orphan receptors remains to be resolved. An interesting parallel can be drawn with the Drosophila orphan receptor DHR38, which has been shown recently to be the insect homolog of NGFI-B. DHR38 can form a heterodimer with USP and interfere with the ecdysone response, probably by sequestration of USP (Sutherland et al. 1995).

The role played by NGFI-B in 9cRA-dependent activation of transcription is intriguing for a reason other than
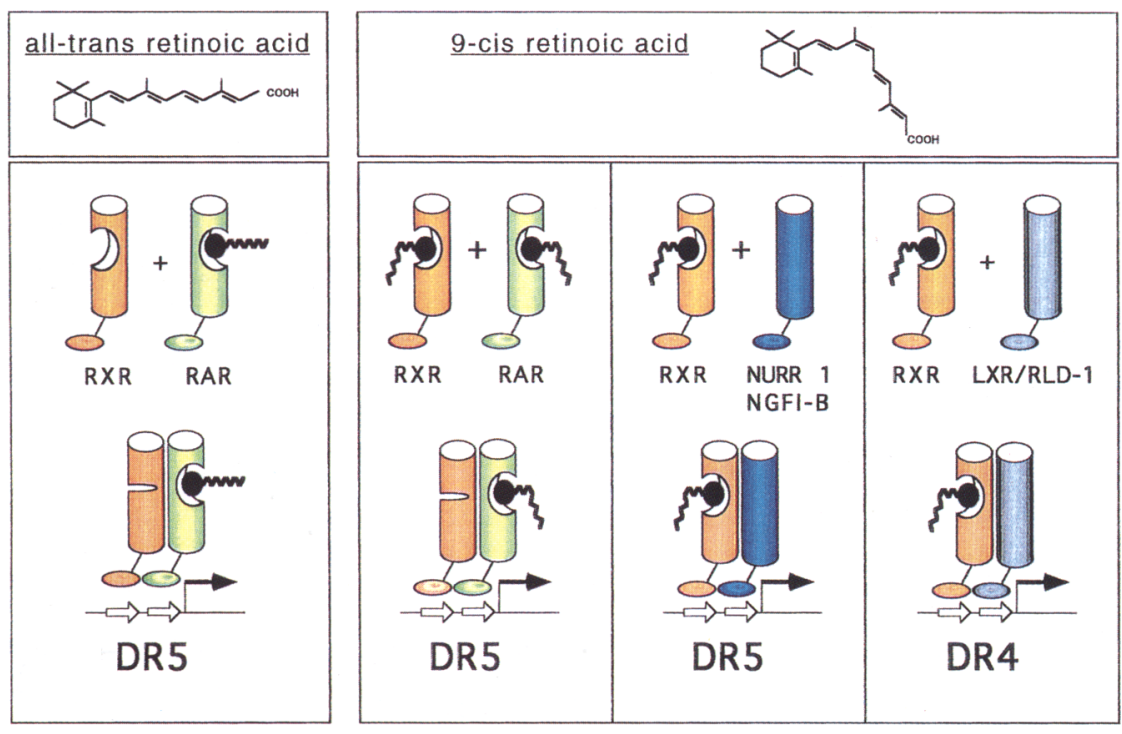

Figure 1. RXR ligand binding and transactivation ability is switched on and off depending on its heterodimeric partner. In vitro, RXR readily binds 9cRA but not atRA. In a complex with RAR and bound to a DR5 element, 9cRA binding to RXR is prevented, presumably because of a conformational change induced by RAR. Hence, RXR acts predominantly or exclusively as an auxiliary factor required for binding and trans-activation by RAR. In contrast, RXR binds 9cRA when complexed with the orphan receptors NGFI-B, the closely related NURR1, or LXR/RLD1) and mediates activation of transcription via DR5 and DR4 elements, respectively. 
its potential role as a mediator of 9cRA action and as a competitor for RXR auxiliary factor action. NGFI-B is one of the immediate early genes induced by growth factors (Hazel et al. 1988; Milbrandt 1988). Therefore, there is a link between a growth factor-induced receptor and 9cRA inducibility. Thus far, the effects of retinoids have been associated mostly with cell growth inhibition and cell differentiation (for recent review, see Mangelsdorf and Evans 1992; Sporn et al. 1994). For example, the action of members of the AP-1 gene family is controlled by growth factors and antagonized by retinoids (Fanjul et al. 1994; Chen et al. 1995). A convergence of growth factor-regulated signaling pathways and retinoid-regulated transcription adds an additional layer of control between these different systems involved in the cell metabolism.

In conclusion, these recent studies uncover novel 9cRA-specific signaling pathways and provide insight into combinatorial complexity implicit in the highly pleiotropic effects of RA signaling.

\section{Acknowledgments}

We are grateful to Francis Stewart for invaluable discussions and critical reading of the manuscript. B.P.L. is supported by a postdoctoral fellowship from the Medical Research Council of Canada.

\section{References}

Apfel, R., D. Benbrook, E. Lernhardt, M.A. Ortiz, G. Salbert, and M. Pfahl. 1994. A novel orphan receptor specific for a subset of thyroid hormone-responsive elements and its interaction with the retinoid/thyroid hormone receptor subfamily. Mol. Cell. Biol. 14: 7025-7035.

Beato, M. 1989. Gene regulation by steroid hormones. Cell 56: 335-344.

Brent, G.A., P.R. Larsen, J.W. Harney, R.J. Koenig, and D.D. Moore. 1989. Functional characterization of the rat growth hormone promoter elements required for induction by thyroid hormone with and without a co-transfected $\beta$ type thyroid hormone receptor. J. Biol. Chem. 264: 178-182.

Bugge, T.H., J. Pohl, O. Lonnoy, and H.G. Stunnenberg. 1992. $\operatorname{RXR} \alpha$, a promiscuous partner of retinoic acid and thyroid hormone receptors. EMBO I. 11: 1409-1418.

Chen, J.-Y., S. Penco, J. Ostrowski, P. Balaguer, M. Pons, J.E. Starret, P. Reczek, P. Chambon, and H. Gronemeyer. 1995. RAR-specific agonist/antagonists which dissociate transactivation and AP-1 transrepression inhibit anchorage-independent cell proliferation. EMBO /. 14: 1187-1197.

Chen, Z.P., L. Shemshedini, B. Durand, N. Noy, P. Chambon, and H. Gronemeyer. 1994. Pure and functionally homogeneous recombinant retinoid $\mathrm{X}$ receptor. /. Biol. Chem. 269: 25770-25776.

Davis, K.D., T.J. Berrodin, J.E. Stelmach, J.D Winkler, and M.A. Lazar. 1994. Endogenous retinoid X receptors can function as hormone receptors in pituitary cells. Mol. Cell. Biol. 14: 7105-7110.

de Thé, H., M.d.M. Vivanco Ruiz, P. Tiollais, H. Stunnenberg, and A. Dejean. 1990. Identification of a retinoic acid responsive element in the retinoic acid receptor $\beta$ gene. Nature 343: $177-180$.

Durand, B., M. Saunders, P. Leroy, M. Leid, and P. Chambon.
1992. All-trans and 9-cis retinoic acid induction of CRABPII transcription is mediated by RAR-RXR heterodimers bound to DR1 and DR2 repeated motifs. Cell 71: 73-85.

Fanjul, A., M.I. Dawson, P.D. Hobbs, L. Jong, J.F. Cameron, E. Harlev, G. Graupner, X.P. Lu, and M. Pfahl. 1994. A new class of retinoids with selective inhibition of AP-1 inhibits proliferation. Nature 372: 107-111.

Forman, B.M., K. Umesono, J. Chen, and R.M. Evans. 1995a. Unique response pathways are established by allosteric interactions among nuclear hormone receptors. Cell 81: 541550.

Forman, B.M., E. Goode, J. Chen, A.E. Oro, D.J. Bradley, T. Perlmann, D.J. Noonan, L.T. Burka, T. McMorris, W.W. Lamph, R.M. Evans, and C. Weinberger. 1995b. Identification of a nuclear receptor that is activated by farnesol metabolites. Cell 81: 686-687

Giguère, V., E.S. Ong, P. Segui, and R.M. Evans. 1987. Identification of a receptor for the morphogen retinoic acid. Nature 330: 624-629.

Green, S., P. Walter, V. Kumar, A. Krust, J.M. Bonert, and P. Chambon. 1986. Human estrogen receptor cDNA: sequence, expression and homology to v-erb A. Nature 320: 134-139.

Hazel, T.G., D. Nathans, and L.F. Lau. 1988. A gene inducible by serum growth factors encodes a member of the steroid and thyroid hormone receptor superfamily. Proc. Natl. Acad. Sci. 85: 8444-8448.

Heyman, R.A., D.J. Mangelsdorf, J.A. Dyck, R. Stein, G. Eichele, R.M. Evans, and C. Thaller. 1992. 9-Cis retinoic acid is a high affinity ligand for the retinoid X receptor. Cell 68: 397406.

Hollenberg, S.M., C. Weinberger, E.S. Ong, G. Cerelli, A. Oro, R. Lebo, E.B. Thomson, M.G. Rosenfeld, and R.M. Evans. 1985. Primary structure and expression of a functional human glucocorticoid receptor cDNA. Nature 318: 635-641.

Issemann, I. and S. Green. 1990. Activation of a member of the steroid hormone receptor superfamily by peroxisome proliferators. Nature 347: 645-650.

Keller, H., C. Dreyer, J. Medin, A. Mahfoudi, K. Ozato, and W. Wahli. 1993. Fatty acids and retinoids control lipid metabolism through activation of peroxisome proliferator-activated receptor-retinoid X receptor heterodimers. Proc. Natl. Acad. Sci. 90: 2160-2164.

Kliewer, S.A., K. Umesono, D.J. Mangelsdorf, and R.M. Evans. 1992a. Retinoid X receptor interacts with nuclear receptors in retinoic acid, thyroid hormone and vitamin D3 signalling. Nature 355: 446-449.

Kliewer, S.A., K. Umesono, D.J. Noonan, R.A. Heyman, and R.M. Evans. 1992b. Convergence of 9-cis retinoic acid and peroxisome proliferator signalling pathways through heterodimer formation of their receptors. Nature 358: 771-774.

Koelle, M.R. 1992. "Molecular analysis of the Drosophila ecdysone receptor complex." Ph.D. thesis, Stanford University, Stanford, CA.

Kurokawa, R., V.C. Yu, A. Näär, S. Kyakumoto, Z. Han, S. Silverman, M.G. Rosenfeld, and C.K. Glass. 1993. Differential orientations of the DNA-binding domain and carboxy-terminal dimerization interface regulate binding site selection by nuclear receptor heterodimers. Genes \& Dev. 7: 1423-1435.

Kurokawa, R., J. DiRenzo, M. Boehm, J. Sugarman, B. Gloss, M.G. Rosenfeld, R.A. Heyman, and C.K. Glass. 1994. Regulation of retinoid signalling by receptor polarity and allosteric control of ligand binding. Nature 371: 528-531.

Lehmann, J.M., L. Jong, A. Fanjul, J.F. Cameron, X.P. Lu, P. Haefner, M.I. Dawson, and M. Pfahl. 1992. Retinoids selective for retinoid $\mathrm{X}$ receptor response pathways. Science 258: 1944-1946. 
Leid, M., P. Kastner, R. Lyons, H. Nakshatri, M. Saunders, T. Zacharewski, J.-Y. Chen, A. Staub, J.-M. Garnier, S. Mader, and P. Chambon. 1992. Purification, cloning, and RXR identity of a HeLa cell factor with which RAR or TR heterodimerizes to bind target sequences efficiently. Cell 68: 377-395.

Levin, A.A., L.J. Sturzenbecker, S. Kazmer, T. Bosakowski, C. Huselton, G. Allenby, J. Speck, C. Kratzeisen, M. Rosenberger, A. Lovey, and J.F. Grippo. 1992. 9-Cis retinoic acid stereoisomer binds and activates the nuclear receptor RXR alpha. Nature 355: 359-361.

Mader, S., J.Y. Chen, Z. Chen, J. White, P. Chambon, and H. Gronemeyer. 1993. The patterns of binding of RAR, RXR and TR homo- and heterodimers to direct repeats are dictated by the binding specificites of the DNA binding domains. $E M B O$ I. 12: 5029-5041.

Mangelsdorf, D.J. and R.M. Evans. 1992. Retinoic acid receptors as transcription factors. In Transcriptional regulation (ed. S. McKnight and K.R. Yamamoto/, pp. 1137-1167. Cold Spring Harbor Laboratory Press, Cold Spring Harbor, NY.

Mangelsdorf, D.J., E.S. Ong, J.A. Dyck, and R.M. Evans. 1990. Nuclear receptor that identifies a novel retinoic acid response pathway. Nature 345: 224-229.

Marks, M.S., P.L. Hallenbeck, T. Nagata, J.H. Segars, E. Appella, V.M. Nikodem, and K. Ozato. 1992. H-2RIIBP (RXRß) heterodimerization provides a mechanism for combinatorial diversity in the regulation of retinoic acid and thyroid hormone responsive genes. EMBO I. 11: 1419-1435

McCollum, E.V. and M. Davis. 1913. The necessity of certain lipins in the diet during growth. J. Biol. Chem. 15: 167-175.

McDonnell, D.P., D.J. Manglesdorf, J.W. Pike, M.R. Haussler, and B.W. O'Malley. 1987. Molecular cloning of cDNA encoding the avian receptor for vitamin D. Science 235: 1214 1217.

Miesfeld, R., S. Okret, A.C. Wikstrom, O. Wrange, J.A. Gustafsson, and K.R. Yamamoto. 1984. Characterization of a steroid hormone receptor gene and mRNA in wild-type and mutant cells. Nature 312: 779-781.

Milbrandt, J. 1988. Nerve growth factor induces a gene homologous to the glucocorticoid receptor gene. Neuron 1: 183188.

Näär, A.M., J.-M. Boutin, S.M. Lipkin, V.C. Yu, J.M. Holloway, C.K. Glass, and M.G. Rosenfeld. 1991. The orientation and spacing of core DNA-binding motifs dictate selective transcriptional responses to three nuclear receptors. Cell 65: 1267-1279.

Oro, A.E., M. McKeown, and R.M. Evans. 1990. Relationship between the product of the Drosophila ultraspiracle locus and vertebrate retinoid X receptor. Nature 347: 298-301.

Osborne, T.B. and L.B. Mendel. 1913. The relation of growth to the chemical constituents of the diet. J. Biol. Chem. 15: 311326.

Perlmann, T. and L. Jansson. 1995. RXR-NGFI-B/NURR1 heterodimerization defines a novel mechanism for convergence between vitamin A and growth factor signaling pathways. Genes \& Dev. 9: 769-782.

Perlmann, T., P.N. Rangarajan, K. Umesono, and R.M. Evans. 1993. Determinants for selective RAR and TR recognition of direct repeat HREs. Genes \& Dev. 7: 1411-1422.

Petkovich, M., N.J. Brand, A. Krust, and P. Chambon. 1987. A human retinoic acid receptor which belongs to the family of nuclear receptors. Nature 330: $444-450$.

Predki, P.F., D. Zamble, B. Sarkar, and V. Giguere. 1994. Ordered binding of retinoic acid and retinoid-X receptors to asymmetric response elements involves determinants adjacent to the DNA-binding domain. Mol. Endocrinol. 8: 31-39.
Qi, J.S., Y.V. Desai, M.E. Greene, B.M. Raaka, and H.H. Samuels. 1995. The ligand-binding domains of the thyroid hormone/retinoid receptor gene subfamily function in vivo to mediate heterodimerization, gene silencing, and transactivation. Mol. Cell. Biol. 15: 1817-1825.

Rastinejad, F., T. Perlmann, R.M. Evans, and P.B. Sigler. 1995. Structural determinants of nuclear receptor assembly on DNA direct repeats. Nature 375: 203-211.

Sap, J., A. Muñoz, K. Damm, Y. Goldberg, J. Ghysdael, and B. Vennström. 1986. The c-erb A protein is a high-affinity receptor for thyroid hormone. Nature 324: 635-640.

Shea, M.J., M.J. Shea, D.L. King, M.J. Conboy, B.D. Mariani, and F. Kafatos. C. 1990. Proteins that bind to Drosophila chorion cis-regulatory elements: A new $\mathrm{C}_{2} \mathrm{H}_{2}$ zinc finger protein and a $\mathrm{C}_{2} \mathrm{C}_{2}$ steroid receptor-like component. Genes \& Dev. 4: $1128-1140$.

Song, C., J.M. Kokontis, R.A. Hiipakka, and S. Liao. 1994. Ubiquitous receptor: A receptor that modulates gene activation by retinoic acid and thyroid hormone receptors. Proc. Natl. Acad. Sci. 91: 10809-10813.

Sporn, M.B., A.B. Roberts, and D.S. Goodman. 1994. The retinoids. Raven Press, New York.

Stunnenberg, H.G. 1993. Mechanisms of transactivation by retinoic acid receptors. BioEssays 15: 309-315.

Sutherland, J.D., T. Kozlova, G. Tzertzinis, and F.C. Kafatos. 1995. DHR38: A new partner for Drosophila USP suggests an unexpected role for NGFI-B-type nuclear receptors. Proc. Natl. Acad. Sci. (in press).

Teboul, M., E. Enmark, Q. Li, A.C. Wikstrom, M. Pelto-Huikko, and J.- $\AA$ Gustafsson. 1995. OR-1, a member of the nuclear receptor superfamily that interacts with the 9-cis-retinoic acid receptor. Proc. Natl. Acad. Sci. 92: 2096-2100.

Thomas, H.E., H.G. Stunnenberg, and A.F. Stewart. 1993. Heterodimerisation of the Drosophila ecdysone receptor with retinoid X receptor and Ultraspiracle. Nature 362: 471-475.

Tugwood, J.D., I. Issemann, R.G. Anderson, K.R. Bundell, W.L. McPheat, and S. Green. 1992. The mouse peroxisome proliferator activated receptor recognizes a response element in the $5^{\prime}$ flanking sequence of the rat acyl CoA oxidase gene. EMBO I. 11: 433-439.

Umesono, K., K.K. Murakami, C.C. Thompson, and R.M. Evans. 1991. Direct repeats as selective response elements for the thyroid hormone, retinoic acid and vitamin $D$ receptors. Cell 65: 1255-1266.

Valćrcel, R., H. Holz, C. García Jiménez, D. Barettino, and H.G. Stunnenberg. 1994. Retinoid-dependent in vitro transcription mediated by the RXR/RAR heterodimer. Genes \& Dev. 8: 3068-3079.

Vivanco Ruiz, M.d.M., T. Bugge, P. Hirschmann, and H.G. Stunnenberg. 1991. Functional characterization of a natural element for retinoic acid. EMBO I. 10: 3829-3838.

Weinberger, C., C.C. Thompson, E.S. Ong, R. Lebo, D. Gruol, and R.M. Evans. 1986. The c-erb A gene encodes a thyroid hormone receptor. Nature 324: 641-646.

Willy, P.J., K. Umesono, E.S Ong, R.M. Evans, R.A. Heyman, and D.J. Mangelsdorf. 1995. LXR, a nuclear receptor that defines a distinct retinoid-response pathway. Genes \& Dev. 9: 1033-1045.

Wilson, T.E., R.E. Paulsen, K.A. Padgett, and J. Milbrandt. 1992. Participation of non-Zinc finger residues in DNA binding by two nuclear orphan receptors. Science 256: 107-110.

Yao, T.-P., W.A. Segraves, A.E. Oro, M. McKeown, and R.M. Evans. 1992. Drosophila ultraspiracle modulates ecdysone receptor function via heterodimer formation. Cell 71: 63-72.

Yao, T.P., B.M. Forman, Z. Jiang, L. Cherbas, J.D. Chen, M. McKeown, P. Cherbas, and R.M. Evans. 1993. Functional 
ecdysone receptor is the product of EcR and Ultraspiracle genes. Nature 366: 476-479.

Yu, V.C., C. Delsert, B. Andersen, J.M. Holloway, O.M. Devary, A.M. Näär, S.Y. Kim, J.-M. Boutin, C.K. Glass, and M.G. Rosenfeld. 1991. RXR $\beta$ : A coregulator that enhances binding of retinoic acid, thyroid hormone and vitamin $D$ receptors to their cognate response elements. Cell 67: 1251-1266.

Zechel, C., X.-Q. Shen, P. Chambon, and H. Gronemeyer. 1994a. Dimerization interfaces formed between the DNA binding domains determine the cooperative binding of RXR/ RAR and RXR/TR heterodimers to DR5 and DR4 elements. EMBO I. 13: 1414-1424.

Zechel, C., X.-Q. Shen, J.-Y. Chen, Z.-P. Chen, P. Chambon, and $\mathrm{H}$. Gronemeyer. 1994b. The dimerization interfaces formed between the DNA binding domains of RXR, RAR and TR determine the binding specificity and polarity of the fulllength receptors to direct repeats. $E M B O I$. 13: 1425-1433.

Zhang, X.K., B. Hoffmann, P.B. Tran, G. Graupner, and M. Pfahl 1992a. Retinoid $X$ receptor is an auxiliary protein for thyroid hormone and retinoic acid receptors. Nature 355: 441-446.

Zhang, X., J. Lehmann, B. Hoffmann, M.I. Dawson, J. Cameron, G. Graupner, T. Hermann, P. Tran, and M. Pfahl. 1992b. Homodimer formation of retinoid $\mathrm{X}$ receptor induced by 9-cis retinoic acid. Nature 358: 587-591. 


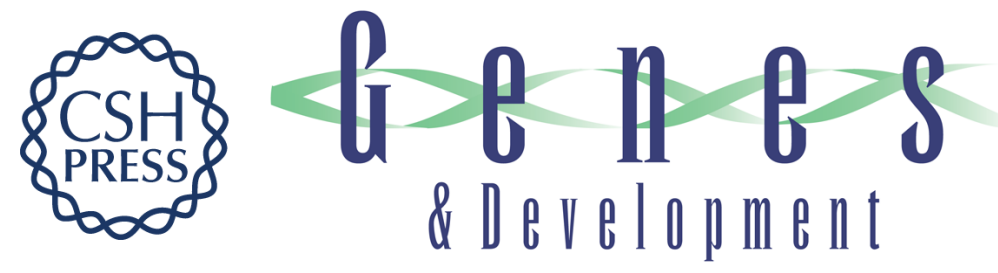

\section{9-cis retinoic acid signaling: changing partners causes some excitement.}

B P Leblanc and H G Stunnenberg

Genes Dev. 1995, 9:

Access the most recent version at doi:10.1101/gad.9.15.1811

References This article cites 62 articles, 20 of which can be accessed free at:

http://genesdev.cshlp.org/content/9/15/1811.full.html\#ref-list-1

License

Email Alerting

Service

Receive free email alerts when new articles cite this article - sign up in the box at the top right corner of the article or click here.

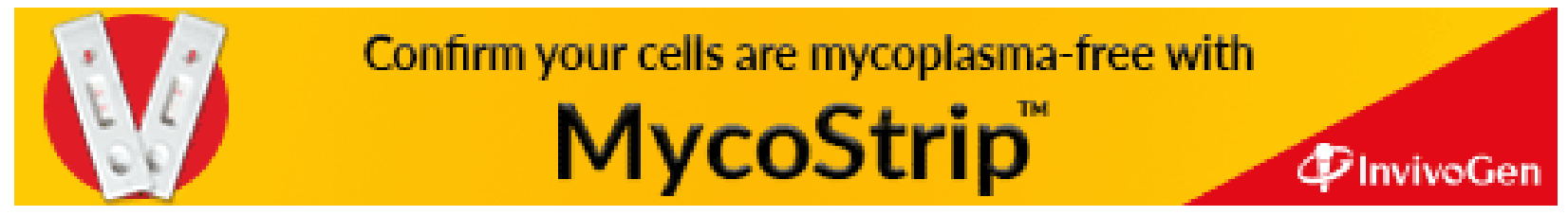

